\title{
Multiple, concurrent or subsequent dysreactive and autoimmune disorders. Potential clinical-patogenetic correlations, and systemic infectious complications
}

\author{
Roberto Manfredi
}

From $16^{\text {th }}$ International Symposium on HIV and Emerging Infectious Diseases

Marseille, France. 24-26 March 2010

\section{Background}

Since mid-sixties, the association between miasthenia gravis, tymectomia for the disease control, and development of autoimmune disorders (i.e. systemic lupus erythematosus, ulcerative cholitis, rheumatoid arthritis, lichen planus), is known, while the relationship with the occurrence of systemic infectious complications is less lnown (underlying immunodeficiency, jatrogenic immunosuppression?).

\section{Methods}

A 26-y-old female patient (p), with a post-thyroiditis hypotireodism, polycystic oophoritis, and a diagnosis of myasthenia gravis posed 4 y before, developed an ilealcolonic Chron's disease treated since 2 mo with steroids.

\section{Results}

When moved to our Infectious Disease Division due to septic hyperpyrexia, not responsive to an initial empiric antimicrobial therapy, and with a presumed allergictoxic rash, underwent a further workup. An evident leukocyotosis (WBC 23,550/ $\mu \mathrm{L}, 88.3 \%$ neutrophils), was associated with increased ESR (86), mild hepatocytolisis, hemorrhagic conjunctivitis, and nodular erythema at lower limbs. An ultrasonographic-CT scan suggested a multifocal pyelonephritis, comfirmed by the isolation of E. coli at urinalysis. Combined, full-dose i.v. cefotaximemetronidazole, was changed upon discharge with

Correspondence: Roberto.manfredi@unibo.it

Infectious Diseases, University of Bologna, S. Orsola Hospital, Bologna, Italy ciprofloxacin, and with the reintroduction of steroideal therapy for Chron's disease.

\section{Discussion}

A large number of predisposing conditions make subjects suffering from autoimmune/dysreactive disorders prone to develop even severe infectious complications, including the frequent immunosuppressive therapies, and the multiple immunodeficiencies detected at the time of diagnosis of these conditions. In the reported p, an autoimmune thryroiditis, a myasthenia gravis, a Crohn's disease, and an erytema nodosum were disclosed in a young female $\mathrm{p}$ aged 26. Consultants requested of diagnosis and management of complications, should take into consideration the heterogeneic, systemic background of each disease presentation, and their possible complications, with a proportionally elevated risk of infectious diseases, which take advantage from the chronic administration of steroids or other immunosuppressive drugs, and the unbalanced immune system, usually shifted towards a Th1 response, which tends to balance the increased Th2 activity typical of autoimmune disorders. As known, $\mathrm{p}$ with chronic inflammatory bowel diseases suffer from myasthenia gravis with a greater frequency $v s$ the general population. From a pathogenetic point of view, the intrathymic maturation process of $\mathrm{T}$-lymphocytes is altered during myasthenia gravis, while intyrathymic B-lymphocyte abnormalities may contribute to the onset of autoimmune disorders. In cases like ours, the concurrence of 
multiple disorders may complicate the differential diagnosis, and hamper a prompt recognition and management of potentially severe infectious complications.

Published: 11 May 2010

doi:10.1186/1742-4690-7-S1-P192

Cite this article as: Manfredi: Multiple, concurrent or subsequent dysreactive and autoimmune disorders. Potential clinical-patogenetic correlations, and systemic infectious complications. Retrovirology 2010 7(Suppl 1):P192.

Submit your next manuscript to BioMed Central and take full advantage of:

- Convenient online submission

- Thorough peer review

- No space constraints or color figure charges

- Immediate publication on acceptance

- Inclusion in PubMed, CAS, Scopus and Google Scholar

- Research which is freely available for redistribution

Submit your manuscript at www.biomedcentral.com/submit 